\title{
A study of histopathology of H. Pylori gastritis in relation To H. pylori density in gastric biopsies
}

\author{
Subramanian K.S. ${ }^{1}$, Shambavi J.J. ${ }^{2}$, Boopathy V. ${ }^{3}$ \\ ${ }^{1}$ Dr. Kalaivani Selvi Subramanian, Assistant Professor, Department of Pathology, ${ }^{2}$ Dr. J. Jeya Shambavi, Associate \\ Professor, Department of Pathology, ${ }^{3}$ Dr. Vinoth Boopathy, Consultant Gastroenterologist, Department of Medical \\ Gastroenterology; all authors are affiliated with Aarupadai Veedu Medical College and Hospital, Kirumampakkam, \\ Puducherry, India.
}

Corresponding Author: Dr. J. Jeya Shambavi, Associate Professor, Department of Pathology, Aarupadai Veedu Medical College and Hospital, Kirumampakkam, Puducherry, India. E-mail: jeenushambavi@gmail.com

\begin{abstract}
Introduction: Helicobacter pylori (H. pylori) is of major concern today and is characterized by mucosal infiltration by neutrophils, mononuclear cells and can cause atrophy and intestinal metaplasia which in long term can predispose to gastric carcinoma or lymphoma. Aims of the study: To evaluate the various histopathological parameters in H. pylori induced gastritis and to correlate with H. pylori density. Materials and Methods: This is a Cross sectional descriptive study conducted in the Department of Pathology and Medicine, which included 50 gastric biopsies that was diagnosed as H. Pylori gastritis for a period of 1 year from January 2017 to December 2017. Histopathological variables like Mononuclear cell infiltration, neutrophilic infiltrate, Atrophy, Density of H. pylori were graded according to updated Sydney system. statistical analysis was done using spearman rank correlation test. Results: There were 50 cases of $\mathrm{H}$. pylori gastritis diagnosed during the study period. The age of the patients ranged from 9 to 75 years with male: female ratio of 2.3:1. Atrophy was seen in 25 cases (50\%). Mononuclear cell infiltration was seen in all 50 cases $(100 \%)$. Neutrophilic activity was seen in all 50 cases (100\%). Mild activity was seen in $27(54 \%)$ cases. Moderate activity in 10 $(20 \%)$ cases and severe activity in $13(26 \%)$ cases. H. pylori density was mild in $29(58 \%)$ cases, moderate in $10(20 \%)$ cases and severe in $11(22 \%)$ cases. H. pylori density showed significant correlation with neutrophilic activity. Conclusion: H. pylori density has significant correlation with severity of neutrophilic activity. Chronic inflammation, metaplasia and atrophy did not show significant correlation with H. pylori density.
\end{abstract}

Key words: Gastritis, H. pylori density, Modified Sydney system, Neutrophilic activity

\section{Introduction}

Gastritis is a common condition with many etiologies and classifications. Helicobacter pylori (H. pylori) is of major concern today because it is proven that $\mathrm{H}$. pylori is the principal cause of chronic gastritis, peptic ulcer diseases, gastric cancer and lymphoproliferative disorders [1]. One-half of the world's population has $\mathrm{H}$. pylori infection, with an estimated prevalence of more than $90 \%$ in developing countries [2]. In our country, the reported prevalence of $\mathrm{H}$. pylori ranged from $30 \%$ to $67 \%$ [2]. H. pylori strains can induce interleukin release from gastric epithelial cells which is a chemotactic factor for neutrophils that infiltrates the mucosa. H. pylori infection is characterized by mucosal infiltration by neutrophils, mononuclear cells and can cause atrophy and intestinal metaplasia which in long term can predispose to gastric carcinoma.

Manuscript received: $10^{\text {th }}$ May 2019

Reviewed: $20^{\text {th }}$ May 2019

Author Corrected: $27^{\text {th }}$ May 2019

Accepted for Publication: $31^{\text {st }}$ May 2019

\section{Aims of the Study}

1. To evaluate the various histopathological parameters in $\mathrm{H}$. pylori induced gastritis.

2. To correlate the H.pylori density with the various histopathological parameters associated with H.pylori gastritis.

\section{Materials and Methods}

Setting: Department of Pathology and Medicine

Duration:1 year from January 2017 to December 2017.

Type of study: Cross sectional descriptive study.

Sampling Methods:All consecutive samples of endoscopic gastric biopsies were included during the study period

Inclusion criteria: Endoscopic gastric biopsies positive for $\mathrm{H}$. pylori.

Pathology Update: Tropical Journal of Pathology \& Microbiology Available online at: www.medresearch.in 362 | P a g e 
Original Research Article

Exclusion criteria: Endoscopic biopsies negative for H.pylori, Malignancy

Data Analysis: Statistical analysis was done using SPSS software version 24. The frequency of distribution of various histopathological parameters were tabulated. The correlation of $\mathrm{H}$. pylori density was done with other histopathological parameters using spearman rank correlation test.

Ethical consideration: Ethical clearance was obtained from Institutional ethical committee.

The biopsy specimens received were fixed in $10 \%$ buffered formalin, processed, oriented on edge and embedded in paraffin wax. Sections were cut in sequential $4 \mathrm{~mm}$ sections and were stained with Hematoxylin and Eosin and modified Giemsa stains.

Gastric biopsies which are negative for H. pylori were excluded from the study.

The histopathological evaluation was done and following features were evaluated:

Mononuclear cell infiltration, neutrophilic infiltrate, Atrophy, Density of H. pylori.

All variables were graded according to updated Sydney system. [3-5]

\section{Mononuclear cell infiltration was scored as follows:}

$0=$ Occasional lymphocytes and plasma cells or at a level considered normal (upto 5/HPF).
$1=$ Mild increase in mononuclear cells (6-10/HPF).

$2=$ Moderate increase in mononuclear cells (I0-20/ HPF).

$3=$ Diffuse increase in mononuclear cells $(>20 / \mathrm{HPF})$.

Neutrophilic infiltrate (Activity) was scored as follows:

$0=$ No extra vascular neutrophils.

$1=$ Scattered in the lamina propria only.

$2=$ Neutrophils infiltrating a minority of gastric pits

$3=$ Neutrophils infiltrating majority of gastric pits/

infiltrate with in foveolar lumen.

Atrophy is scored as the percentage of atrophic glands. Non-metaplastic and metaplastic subtypes are considered together.

0 - No atrophy, $0 \%$,

1-Mild atrophy, $1-30 \%$

2- Moderate atrophy, 31-60\%

3- Severe atrophy, $>60 \%$,

The density of $\mathrm{H}$ pylori was scored as follows:

$0=$ Not identified.

$1=$ Rare organisms present.

2 =Organisms found in many but not all high fields.

$3=$ Plentiful organisms in all fields.

Ifareas with widely different scores were present on the same specimen, an average based on the general evaluation of the sample was used.

\section{Results}

There were 50 cases of $\mathrm{H}$. pylori gastritis diagnosed during the study period. The age of the patients ranged from 9 to 75 years. There were 35 males and 15 females with male: female ratio of 2.3:1. Endoscopic examination revealed 44 (88\%) cases involving the antropyloric region with erosions and ulcer, two (4\%) cases involved lesser curvature, two (4\%) cases involved body of stomach and two (4\%) cases presented as pangastritis. Scoring done according to updated Sydney system is tabulated in Table 1 .

Table-1: Modified Sydney scoring of histopathological parameters in H. pylori induced gastritis.

\begin{tabular}{|c|c|c|c|c|}
\hline & $\begin{array}{c}\text { Mononuclearcell } \\
\text { infiltration (\%) }\end{array}$ & $\begin{array}{c}\text { Neutrophilicactivity } \\
(\%)\end{array}$ & $\begin{array}{c}\text { Atrophy } \\
(\%)\end{array}$ & H. pyloridensity (\%) \\
\hline Score 0 & 0 & 0 & 50 & 0 \\
\hline Score 1 & 2 & 54 & 28 & 58 \\
\hline Score 2 & 12.3 & 20 & 20 & 20 \\
\hline Score 3 & 85.7 & 26 & 2 & 22 \\
\hline
\end{tabular}

Atrophy was seen in 25 cases (50\%). No atrophy was seen in 25 cases (50\%). Mild atrophy was seen in $14(28 \%)$ cases. Moderate atrophy in $10(20 \%)$ cases and severe atrophy in $1(2 \%)$ case. Five cases $(10 \%)$ were associated with intestinal metaplasia. 


\section{Original Research Article}

Mononuclear cell infiltration was seen in all 50 cases $(100 \%)$. Mild inflammation was seen in $1(2 \%)$ case. Moderate inflammation in $7(12.3 \%)$ cases and severe inflammation in $42(85.7 \%)$ cases. Neutrophilic activity was seen in all 50 cases (100\%). Mild activity was seen in $27(54 \%)$ case. Moderate activity in $10(20 \%)$ cases and severe activity in 13 (26\%) cases. H.Pylori density was mild in $29(58 \%)$ cases, moderate in $10(20 \%)$ cases and severe in $11(22 \%)$ cases. H. pylori density showed significant correlation with neutrophilic activity $(\mathrm{p}<0.05)$. Dysplasia was seen in $2(4 \%)$ cases, parietal cell hyperplasia was seen in $2(4 \%)$ cases.

\section{Discussion}

Helicobacter pyloriis a gram-negative bacterium colonizing the human gastric mucosa, and causes a variety of clinical outcomes ranging from asymptomatic carriage to gastritis, peptic ulcers, cancer and lymphoproliferative disorders. $\mathrm{H}$. pylori gastritis is characterized by mucosal infiltration by neutrophils and mononuclear cells. Although a variety of tests are available for rapid detection like rapid urease test; histomorphology and culture remains gold standard as rapid urease test can sometimes be negative in case of low bacilli load. And culture though highly sensitive and specific takes longer time duration [2].

H. pylori infection induce interleukin release from gastric epithelial cells especially interleukin 8 (IL- 8) which is a chemotactic mediator for neutrophilic infiltrate. Various studies have established a causal relationship between IL-8 and neutrophilic infiltration in H. pylori infection [6-9]. Taguchi et al [10] reported the association of the IL-8-251 A/T polymorphism with higher expression of IL-8 protein, severe neutrophil infiltration and increased risk of atrophic gastritis and gastric cancer.

In Sydney system of grading the histopathological parameters assessed are chronic inflammation (chronic gastritis), the activity of the gastritis measured by the presence of polymorphonuclear leucocytes alongside the mononuclear inflammatory infiltrate, intestinal metaplasia, atrophy manifested by the loss of the normal mucosal glands, and the presence of $\mathrm{H}$. pylori organisms [3]. Fareed et al [5] correlated the inflammatory activity with H.pylori density in antrum, corpus and cardia and found neutrophilic activity was most in antrum and least in cardia and also found a direct correlation of neutrophilic activity with the density of $\mathrm{H}$. pylori.

Few authors have found correlation between H.pylori density and chronic inflammation. Kim et al [11], correlated gastritis with $\mathrm{H}$. pylori density in duodenal ulcer and benign gastric ulcer patients and found the inflammatory reaction to $\mathrm{H}$. pylori is stronger in the antrum than in the body. The study also showed that there is a direct relationship between the severity of $\mathrm{H}$. pylori infection and the degree of chronic gastritis. Similarly in a study by Yakoob et al [12], there was a statistically significant correlation between the intensity of $\mathrm{H}$. pylori colonization and chronic gastritis activity. In a study conducted by Ardakani et al [13], on 272 samples of gastric biopsy, there was no significant relationship between the density and volume of $\mathrm{H}$. pylori and the severity of chronic gastritis activity. Choudhary et al [14], also Correlated H. Pylori density with grading of chronic gastritis in 251 patients and showed a lack of correlation. Park et al[15], in Korea, studied the relationship overall between the presence of H. pylori and histological grading of chronic gastritis, including activity, and no association was found between the quantitative grading of $\mathrm{H}$. pylori and the histological grading of chronic gastritis which he attributed could be due to the genetic differences, nutritional habits, and environmental factors between the study populations [11].

In our study there was significant correlation between neutrophilic activity and $\mathrm{H}$. pylori density as found by Fareed et al. But no correlation was observed with $\mathrm{H}$. pylori density and chronic inflammation, atrophy and metaplasia. Those cases associated with intestinal metaplasia had low H.pylori density as explained by the alkaline environment by goblet cells. Otherwise most of the cases showed significant correlation between neutrophilic activity and H.pylori density.

Chronic inflammatory cells did not show any correlation. Presence of lymphoid follicles was observed to be clue to chronic H.pylori infection but did not correlate with density of organisms. Atrophy was also seen to be associated with severity of chronic inflammation than with H.pylori density and neutrophilic activity.

\section{Conclusion}

H.pylori density has significant correlation with severity of neutrophilic activity. Chronic inflammation, metaplasia and atrophy did not show correlation with H.pylori density.

\section{What this study adds to existing knowledge?}

This study highlights the fact that the intensity of neutrophilic infiltration correlates with the H.pylori density and so the disease activity 


\section{Original Research Article}

\section{Contribution by authors}

-Dr. Kalaivani@ Selvi has involved in study design, data collection, analysis and manuscript writing

- Dr. Jeya Shambavi has involved in data collection, analysis and manuscript writing

- Dr. Vinoth has involved in study design, data collection and manuscript editing

Findings: Nil; Conflict of Interest: None initiated Permission from IRB: Yes

\section{References}

1. Uemura $\mathrm{N}$, Okamoto $\mathrm{S}$, Yamamoto $\mathrm{S}$, et al. Helicobacter pylori infection and the development of gastric cancer. N Engl J Med. 2001 Sep 13; 345(11): 784-9. DOI:10.1056/NEJMoa001999

2. Shrestha R, Koirala K, Shiv Raj K, Batajoo KH. Helicobacter Pylori Infection Among Patients with Upper Gastrointestinal Symptoms: Prevalence and Relation to Endoscopy Diagnosis and Histopathology. Journal of Family Medicine and Primary Care. 2014:3 (2): 154-158.doi: 10.4103/2249-4863.137663

3. Dixon MF, Genta RM, Yardley JH, et al. Classification and grading of gastritis. The updated Sydney System. International Workshop on the Histo-pathology of Gastritis, Houston 1994. Am J Surg Pathol. 1996 Oct; 20 (10):1161-81.

4. Pruthi S, Nirupama M, Chakraborti S. Evaluation of gastric biopsies in chronicgastritis: Grading of inflammation by Visual Analogue Scale. Medical Journal of Dr. D.Y. Patil University.2014:7(4):463-467. doi: $10.4103 / 0975-2870.135268$

5. Fareed R, Abbas Z, Shah MA. Effect of Helicobacter pylori density on inflammatory activity in stomach. J Pak Med Assoc. 2000 May;50(5):148-51.

6. Matsushima K, Oppenheim JJ. Interleukin 8 and MCAF: novel inflammatory cytokines inducible by IL 1 and TNF. Cytokine. 1989 Nov;1(1):2-13.

7. Baggiolini M, Walz A, Kunkel SL. Neutrophilactivating peptide $1 /$ Interleukin 8 , a novel cytokine that activates neutrophils. J. Clin. Invest. 1989;84(4):104549.doi: 10.1172/JCI1 14265
8. Bodger K, Bromelow K, Wyatt JI, et al. Interleukin 10 in Helicobacter pylori associated gastritis: immunohistochemical localisation and in vitro effects on cytokine secretion. J Clin Pathol. 2001 Apr;54(4):28592. DOI:10.1136/jcp.54.4.285

9. Godaly G, Proudfoot AE, Offord RE, et al. Role of epithelial interleukin-8 (IL-8) and neutrophil IL-8 receptor A in Escherichia coli-induced transuroepithelial neutrophil migration. Infect Immun. 1997 Aug; 65 (8):3451-6.

10.Taguchi A, Ohmiya N, Shirai K, et al. Interleukin-8 promoter polymorphism increases the risk of atrophic gastritis and gastric cancer in Japan. Cancer Epidemiol Biomarkers Prev. 2005;14(11):2487-2493.doi:10.1158/ 1055-9965.EPI-05-0326

11. Kim N, Choi W.R, C.H, Sheen D.H, Yang S.S, Lee J.Y, Han Y.J, et al. Difference in the Distribution Pattern of Helicobacter pylori and Grade of Gastritis in the Antrum and in the Body between Duodenal Ulcer and Benign Gastric Ulcer Patients.Korean J Intern Med. 2000;15(1): 32-36.doi: 10.3904/kjim.2000.15.1.32

12. Yakoob MY, Hussainy AS. Chronic gastritis and Helicobacter pylori: a histopathological study of gastric mucosal biopsies. J Coll Physicians Surg Pak. 2010 Nov; 20(11):773-5. doi: 11.2010/JCPSP.773775.

13. Ardakani A., Mohammadizadeh F. The study of relationship between Helicobacter pylori density in gastric mucosa and the severity and activity of chronic gastritis. Journal of Research in Medical Sciences. 2006;11(4):282.doi:10.1097/00000478-19961000000001

14. Choudhary CK, Bhanot UK, Agarwal A, et al. Correlation of H. pylori density with grading of chronic gastritis.Indian J Pathol Microbiol. 2001Jul;44(3):325-8

15. Park J, Kim MK, Park SM. Influence of Helicobacter pylori colonization on histological grading of chronic gastritis in Korean patients with peptic ulcer. Korean J Intern Med. 1995 Jul;10(2):125-9. DOI:10. 3904/kjim.1995.10.2.125

\section{How to cite this article?}

Subramanian K.S, Shambavi J.J, Boopathy V. A study of histopathology of H. Pylori gastritis in relation To H. pylori density in gastric biopsies. Trop J Path Micro 2019;5(6):362-365.doi:10.17511/jopm.2019.i06.05. 